\title{
Bibliotecas universitárias: uso de estratégias comunicacionais de combate à desinformação no contexto da pandemia Covid-19
}

\author{
University libraries: use of strategies communications to combat disinformation in the context \\ pandemic Covid-19
}

\begin{abstract}
Vanessa Cristiane Dornelles Vidarte
Especialista em Engenharia de Segurança do Trabalho (EAD) pela Universidade Cândido Mendes, Brasil. Assistente em Administração na Biblioteca Central da Universidade Federal de Santa Maria - UFSM, Brasil. https://orcid.org/0000-0002-0927-7642

E-mail: vanessa.vidarte@ufsm.br

Shana Catiusca Dornelles Vidarte Velasco Mestra pelo Programa de Pós-Graduação em História da Universidade Federal do Rio Grande - FURG, Brasil. Bibliotecária da Biblioteca Central da Universidade Federal de Santa Maria - UFSM, Brasil. https://orcid.org/0000-0002-5504-8429 E-mail: shana_vidarte@hotmail.com
\end{abstract}

\section{Resumo}

O advento da "sociedade informacional" (CASTELLS, 1999) surge dedicando espaço à informação. Embora tão relevante para essa sociedade, o extenso volume de informações veiculadas por meio das mídias sociais favorece a disseminação de informações falsas. Recentemente, a Organização Mundial da Saúde declarou que a pandemia Covid- $19^{1}$ gerou uma infodemia, fenômeno que agrava ainda mais a atual crise de saúde pública. Pensando nisso, este artigo objetiva analisar como as bibliotecas universitárias podem contribuir para controlar a desinformação, através do uso de estratégias comunicacionais. Para tanto, como procedimento metodológico realizou-se uma revisão bibliográfica relacionando os tópicos: sociedade informacional e seus desafios como "pós-verdade" (DELFINO; PINHO NETO; SOUSA, 2019) e infodemia, desinformação e formação da opinião pública, bem como um mapeamento nos sites e mídias sociais de algumas bibliotecas universitárias, no período de paralisação das atividades presenciais. Como resultado, verificamos que a pós-verdade se tornou uma consequência de uma sociedade, dita 'informacional', mas que não sabe usar a informação apropriadamente. Além disso, compreendeuse que a desinformação é uma estratégia de manipulação da opinião pública, visto que interfere na capacidade dos indivíduos de interpretar e avaliar a informação. Depreendeu-se que as bibliotecas estudadas têm utilizado eficazmente estratégias comunicacionais como a publicação de conteúdos informativos nas mídias sociais, que auxiliam os usuários na avaliação crítica das informações recebidas. Conclui-se que as bibliotecas universitárias, como mediadoras dos processos de interação e relacionamento do usuário com a informação, desempenham um importante papel no combate à desinformação.

Palavras-Chave: Bibliotecas universitárias. Desinformação. Estratégias comunicacionais.

\footnotetext{
1 "Doença causada pelo coronavírus denominado SARS-CoV-2 [...] Foi identificada pela primeira vez na China, em dezembro de 2019. No Brasil, em 3 de fevereiro de 2020, a infecção humana pelo novo coronavírus foi declarada Emergência em Saúde Pública de Importância Nacional.” (OLIVEIRA et al., 2020. p.1)
}

Bibl. Esc. em R., Ribeirão Preto, v. 7, n. 2, p. 163-175, 2021.

DOI: 10.11606/issn.2238-5894.berev.2021.184172 
Bibliotecas universitárias: uso de estratégias comunicacionais de combate à desinformação no contexto da pandemia Covid-19

\begin{abstract}
The advent of the "informational society" (CASTELLS, 1999) emerges dedicating space to information. Although so relevant to this society, the extensive volume of information disseminated through social media favors the dissemination of false information. Recently, the World Health Organization declared that the Covid- $19^{2}$ pandemic has generated an infodemic, a phenomenon that further aggravates the current public health crisis. In light of the above, this article aims to analyze how university libraries can contribute to controlling disinformation, through the use of communication strategies. For this purpose, as a methodological procedure a literature review was conducted relating the topics: informational society and its challenges as "post-truth" (DELFINO; PINHO NETO; SOUSA, 2019) and infodemic, misinformation and formation of public opinion, as well as a mapping in the websites and social media of some university libraries, in the period of paralysis of in-person activities. As a result, we verified that post-truth has become a consequence of society, said to be 'informational', but which does not know how to use information properly. Moreover, it was understood that misinformation is a strategy for manipulating public opinion since it interferes with the individuals' ability to interpret and evaluate information. It was found that the libraries studied have effectively used communication strategies such as the dissemination of informational content on social media, which assist users in the critical evaluation of the information received. It is concluded that university libraries, as mediators of the user's interaction and relationship processes with information, play an important role in combating disinformation.
\end{abstract}

Keywords: University libraries. Disinformation. Communication strategies.

\title{
1. Introdução
}

Em virtude do bombardeio de informações que recebemos diariamente, por meio das mídias sociais, espalhar mentiras e distorcer fatos se tornou algo comum. Diante disso, a propagação de informações falsas de forma massiva tem ocasionado impactos negativos nas temáticas relacionadas à saúde e meio ambiente. Particularmente, durante a pandemia Covid19, o fenômeno atingiu uma proporção tão grande que passou a ser descrito pela Organização Mundial da Saúde (OMS) como uma "infodemia".

Concomitantemente, a pandemia Covid-19 ocasionou outra pandemia global de desinformação, a qual " [...] atingiu de forma abrupta as pessoas que possuem carência em competência em informação (CoInfo), ou seja, desconhecimento e/ou inabilidade para o uso e criticidade adequada da informação e suas fontes" (ALMEIDA, 2020, p. 3). Diante disso, a biblioteca universitária, como facilitadora do uso e acesso à informação, pode colaborar em estabelecer estratégias comunicacionais que visam restringir a infodemia.

Desta forma, esse artigo tem como objetivo a realização de uma pesquisa bibliográfica sobre como a sociedade informacional se relaciona com o fenômeno da "pós-verdade", além de

\footnotetext{
2 "Disease caused by the coronavirus named SARS-CoV-2 [...] It was first identified in China in December 2019. In Brazil, on February 3, 2020, human infection by the new coronavirus was declared a Public Health Emergency of National Importance.” (OLIVEIRA et al., 2020. p.1, tradução nossa).
} 
abordar o conceito e os tipos de desinformação e ainda a sua influência na opinião pública. Pesquisou-se também quais estratégias comunicacionais estão sendo desenvolvidas por algumas bibliotecas universitárias no período de paralisação das atividades presenciais. Dessa forma, após um mapeamento nos sites e mídias sociais das bibliotecas, escolheu-se alguns exemplos de estratégias comunicacionais que estão sendo usadas para minimizar os efeitos da desinformação na sociedade.

Neste sentido, o referido artigo subdivide-se em quatro tópicos, sendo o primeiro tópico referente à caracterização da sociedade informacional e sua relação com os fenômenos da pósverdade e da infodemia. No segundo tópico analisaremos os conceitos e os tipos de desinformação e sua interferência na construção da opinião pública. No terceiro tópico será explorado como as bibliotecas universitárias têm se reinventado para continuarem conectadas com seus usuários e as estratégias comunicacionais utilizadas por algumas bibliotecas para combater à desinformação. Por fim, no quarto tópico serão abordadas questões em relação à oferta de informações e dados que auxiliem os usuários na prevenção da desinformação e implementação de boas práticas relacionadas ao combate à pandemia.

\section{Desafios da sociedade informacional}

A Sociedade da Informação promoveu espaços de desenvolvimento de atividades em um novo paradigma tecnológico centralizado na informação (NEMER, 2020). Em concordância, Castells (1999) afirma que a primeira característica dessa sociedade é que a informação é sua matéria-prima.

Nesse contexto, a informação passou a ser monetizada, pois conforme Silveira (2017, p. 15): "as sociedades informacionais são sociedades pós-industriais que tem a economia fortemente baseada em tecnologias que tratam informações como seu principal produto", ou seja, a economia é baseada na produção de bens imateriais que circulam por redes digitais (SILVEIRA, 2017). Observamos a circulação de nossos bens imateriais quando somos frequentemente, surpreendidos por anúncios de vendas não solicitados em nossas redes sociais, ou por ligações e e-mails indesejados de oferta de produtos ou serviços. Ou seja, nossos dados, preferências e intenções são transformados em produtos monetizados pelas plataformas digitais.

Nesse sentido, salienta-se que a economia informacional se caracteriza pelo uso de novas tecnologias, e novas estratégias de organização das informações, como por exemplo, as 
Bibliotecas universitárias: uso de estratégias comunicacionais de combate à desinformação no contexto da pandemia Covid-19

redes sociais (CEZAR; SUAIDEN, 2017). Portanto, as redes sociais ampliaram as dinâmicas dos processos de comunicação e de compartilhamento de informações.

Nesse âmbito, um dos maiores desafios referentes à nova configuração informacional se refere à "incapacidade de analisar e diferenciar com clareza e reflexão o imenso volume de informações a que estão expostos frequentemente, o que pode ser definido, como pósverdade" (DELFINO; PINHO NETO; SOUSA, 2019, p. 6). De acordo com o Dicionário Oxford pós-verdade se refere a circunstâncias em que fatos influenciam menos a opinião pública do que apelos emocionais e às crenças pessoais (PÓS-VERDADE, 2019). Dessa forma, narrativas verídicas são apresentadas de modo a envolver as emoções das pessoas e a consolidar opiniões polarizadas.

No atual cenário pandêmico, observamos que a propagação de informações divergentes e discursos contraditórios ligados à pandemia favorece o fenômeno da pós-verdade, levando os indivíduos a acreditarem naquilo que é mais conveniente para eles, além da formação de opiniões e tomada de decisões baseadas em emoções e concepções pessoais (GOULART; MUÑOZ, 2020). Nesse sentido, aceitamos mais facilmente uma opinião como verdadeira se ela confirma nosso próprio ponto de vista, porque é mais confortável validar nossas crenças do que questioná-las (COUTANT, 2020). Dessa maneira, a opinião pública não é constituída espontaneamente, mas é pautada em interpretações pessoais e sob falsos contextos.

Nesse contexto, a OMS declarou que a pandemia Covid-19 gerou uma enorme infodemia, que se refere ao extenso volume de informações nem sempre verificadas, que dificultam o acesso a fontes e orientações confiáveis quando se precisa. Na era da sociedade informacional, esse fenômeno é potencializado pelas mídias sociais e se alastra rapidamente assim como um vírus (ORGANIZAÇÃO PAN-AMERICANA DA SAÚDE, 2020). As redes sociais propiciaram a democratização da produção de conteúdos. Por conseguinte, a facilidade do compartilhamento de informações de fontes não fidedignas, sobre possíveis remédios e tratamentos para a doença causada pela covid-19, pode gerar graves consequências à saúde pública.

Nessa perspectiva, a infodemia pode agravar a pandemia Covid-19 devido aos seguintes fatos:

Dificulta que fontes idôneas e orientações confiáveis sejam encontradas pelas pessoas de modo geral, pelos responsáveis pela tomada de decisões e por profissionais de saúde quando precisam. As fontes podem ser aplicativos, instituições científicas, sites, blogs, "influenciadores", entre outras. - As pessoas podem se sentir ansiosas, 
deprimidas, sobrecarregadas, emocionalmente exaustas e incapazes de atender a demandas importantes. - Ela pode afetar os processos de tomada de decisões quando se esperam respostas imediatas e não se dedica tempo suficiente para analisar com cuidado as evidências. - Não há controle de qualidade do que é publicado nem, às vezes, do que é usado para agir e tomar decisões. (Organização Pan-Americana da Saúde, 2020, p. 3, grifo nosso).

Diante disso ressalta-se a importância de deter a infodemia. Para esse fim, as mídias sociais devem ser utilizadas para a veiculação de informações verídicas de modo a diminuir os impactos negativos da desinformação na opinião pública.

\section{Desinformação e formação da opinião pública}

As tecnologias digitais de informação e comunicação (TDICs) provocaram mudanças significativas nas formas de comunicação e relacionamento entre as pessoas. Nessa perspectiva, na lógica das mídias sociais é realizado "um perigoso salto que vai da informação - não necessariamente verificada, nem sempre confiável [...] à opinião, ignorando-se o essencial processo de interpretação" (FARIAS; CARDOSO; NASSAR, 2020, p. 229). Dessa forma, as mídias sociais transformaram os processos interpretativos de leitura da informação.

Cipriani (2011, p. 176) define mídia social como "termo usado para descrever sites na internet que possuem conteúdo social, ou seja, são gerados pelas próprias pessoas e normalmente comandados por elas". Nesse sentido, as interações provocadas pelas mídias sociais propiciam o protagonismo dos sujeitos e a larga disseminação de conteúdos, estendendo assim, as oportunidades de geração de informação.

No entanto, a produção massiva de informação produz nos indivíduos saturação e o resultado disso é a superinformação e a desinformação (GÓMEZ, 2015). De acordo com Recuero e Soares (2020): “[...] desinformação é uma informação falsa propositalmente fabricada ou manipulada para enganar um grande público, para causar dano a algo ou alguém [...]". Tendo em vista as reflexões mencionadas pelos autores, compreende-se que a desinformação deturpa a realidade com o objetivo de enganar as pessoas.

Recuero e Soares (2020) classificam os tipos de desinformação levando em consideração se a informação sofreu ou não intervenções:

(1) informação fabricada - Informação completamente falsa, fabricada ou sem nenhuma evidência como, por exemplo, teorias da conspiração; 
Bibliotecas universitárias: uso de estratégias comunicacionais de combate à desinformação no contexto da pandemia Covid-19

(2) informação com enquadramento enganoso - Informações verdadeiras utilizadas para criar um sentido falso devido a forma como são apresentadas e ao tipo de conexões que é realizado a partir delas;

(3) informações manipuladas - Informações parcialmente verdadeiras manipuladas para construir um falso sentido. Por exemplo: imagens verdadeiras manipuladas de modo a acrescentar ou retirar uma informação essencial (RECUERO; SOARES, 2020, p. 6).

Diante disso, conclui-se que os diferentes tipos de desinformação são utilizados para prejudicar a capacidade dos indivíduos em identificar informações falsas. Ademais, segundo Tobias e Corrêa (2019, p. 560) "a informação tem sofrido influência do uso massivo das novas tecnologias, assim como dos novos métodos de comunicação entre os indivíduos e das notícias divulgadas nas mídias sociais". Esse excesso de informação produz uma falsa ilusão de que a sociedade está bem informada, quando na realidade, notícias inverídicas e dados manipulados estão inseridos nesse ambiente informacional.

Como comentam os autores, ao invés de considerar a validade dos fatos, as pessoas são inclinadas a acreditar em opiniões pessoais destacadas na web, o que demonstra a inconfiabilidade dos conteúdos produzidos e difundidos nas mídias sociais (TOBIAS; CÔRREA, 2019). Observa-se que as plataformas de redes sociais têm sido utilizadas para difundir desinformação com o objetivo de "passar uma imagem errada da realidade para fins políticos, militares ou econômicos" (COUTANT, 2020, p. 20). Nesse sentido, a desinformação enfraquece a credibilidade das instituições e mídias tradicionais e, por conseguinte, grupos com posicionamentos e interesses comuns nas plataformas digitais ditam o direcionamento da opinião pública.

\footnotetext{
As construções da opinião pública não se dão de forma linear, nem mesmo de modo individual, porque cada um tem em si um conjunto de experiências absorvidas da experiência do outro. Assim cada opinião individual é também até certo ponto, coletiva, porque cada um de nós tem opiniões refletidas por situações de tempos e espaços não vividos (LIPPMANN, 2010 apud FARIAS; CARDOSO; NASSAR, 2020, p. 211).
}

Conclui-se que diante da troca de informações em tempo real, facilitada pelas mídias sociais, o processo de construção da opinião pública se tornou ainda mais complexo e vulnerável à desinformação. Para atenuar tal problemática, as bibliotecas universitárias possuem o potencial de auxiliar a comunidade a avaliar criticamente as informações recebidas, e desse modo minimizar os efeitos da desinformação na sociedade. 


\section{Estratégias comunicacionais de bibliotecas universitárias contra à desinformação}

A pandemia Covid-19 ocasionou o fechamento imediato das bibliotecas universitárias. Com o distanciamento social, bibliotecas de universidades brasileiras precisaram se adaptar e construir novas formas de interação com os usuários. Muitas bibliotecas têm realizado em suas mídias sociais a divulgação de "lives culturais, círculos de leitura, opções de dramaturgia gratuitas na rede, visitas virtuais a museus e bibliotecas do mundo todo [...] praticando a ação mediadora entre a informação disponível em rede e o usuário que a busca" (KERN, 2020, p. 16 , grifo do autor).

Nesta perspectiva, as mídias sociais se tornaram a principal ferramenta no estabelecimento de estratégias comunicacionais com o público-alvo. Estratégias comunicacionais se referem a "um conjunto de ações de comunicação planejadas que visam atender a determinados objetivos e que, se bem formuladas, implicam metas, ou seja, definem resultados concretos a serem perseguidos" (BUENO, 2015, p. 125). Nesse sentido, as bibliotecas universitárias precisam planejar ações comunicacionais com o objetivo de promover a visibilidade midiática de seus conteúdos e serviços de forma eficaz, e desse modo minimizar a desinformação e a infodemia.

A biblioteca universitária deve ser reconhecida como uma instituição que possui autoridade informacional no ambiente digital. Para tanto, é necessário que os profissionais que nela atuam façam amplo uso das mídias sociais digitais para difundir a informação cientifica a um público cada vez maior (ALMEIDA, 2020). A partir disso, realizou-se um mapeamento dos sites de diferentes bibliotecas universitárias bem como das mídias sociais Facebook e Instagram, e foram selecionadas, a título de exemplo, algumas estratégias comunicacionais que têm sido efetivas para reduzir a desinformação.

Verificou-se que a principal estratégia comunicacional que a Biblioteca Central da Universidade Federal de Santa Maria (BC/UFSM) está utilizando, durante o período de paralisação das atividades presenciais, é a elaboração de drops informativos que são publicados nas redes sociais da Biblioteca Central. Os drops abordam temáticas relacionadas ao meio acadêmico e divulgação de fontes de pesquisa idôneas, além de tópicos relacionados à pandemia, como um modo de combater à desinformação. Dentre esses podemos citar séries de drops sobre: 
Bibliotecas universitárias: uso de estratégias comunicacionais de combate à desinformação no contexto da pandemia Covid-19

$\checkmark$ Tipologia e eficiência das máscaras de proteção individual contra a Covid-19, e importância do uso correto desse EPI;

$\checkmark$ Tipos de testes rápidos para Covid-19;

$\checkmark$ Vacinas em geral e contra a Covid-19: conceito, principais tipos, como funcionam, modo em que são desenvolvidas, e a importância da vacinação;

$\checkmark$ Diferenças e atualizações sobre os tipos de vacina contra a Covid-19;

$\checkmark$ 'Campanha Janeiro Branco' abordando questões relacionadas à saúde mental, impactada fortemente pelo isolamento social e pela fadiga da pandemia, como ansiedade estresse e depressão;

$\checkmark$ Riscos da automedicação e do uso indiscriminado de medicamentos contra a Covid-19. Além disso, há a divulgação de e-books de editoras universitárias de forma gratuita durante o período de quarentena e ciclos de capacitações virtuais em base de dados científicas, organizados pela Divisão de Referência da biblioteca em parceria com editores científicos. Ademais, recentemente foi lançada uma série de postagens, incluindo dicas de leituras, documentários e podcasts sobre infodemia, nas redes sociais da BC/UFSM. O logotipo escolhido para essa série intitulada 'Redes Socais, tecnologias e fake news', é uma imagem com uma foto de pessoas com seus celulares, sem mostrar os rostos delas, indicando a alienação dos indivíduos causada pela tecnologia (UNIVERSIDADE FEDERAL DE SANTA-MARIA, 2021). "Na parte inferior da imagem, há um desenho de smartphone com uma cabeça, com nariz grande, espetando uma folha de jornal, simbolizando fake news" (UNIVERSIDADE FEDERAL DE SANTA MARIA, 2021, p. 1, grifo nosso), conforme ilustrado na figura que segue.

Figura 1: Logotipo da série de posts 'Redes sociais, tecnologias e fake news'.

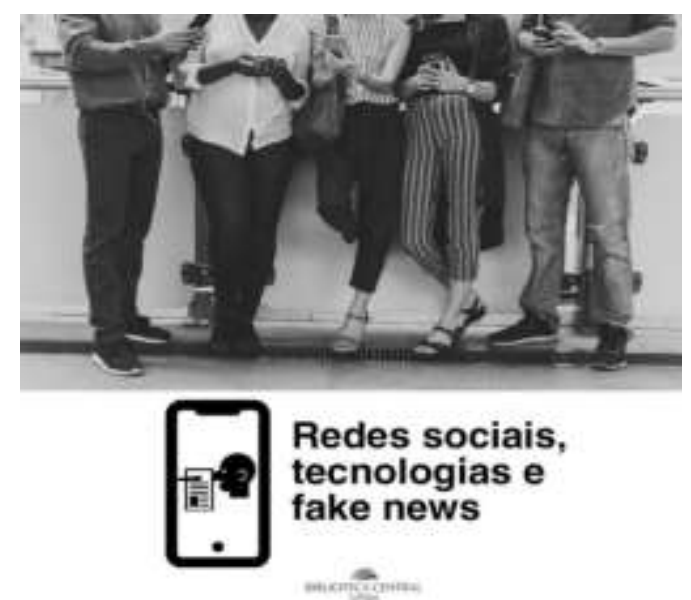

Fonte: Facebook da Biblioteca Central da UFSM. 
O objetivo desta sequência de posts é ilustrar fontes de informação que tratam do tema infodemia, "desde o excesso do consumo de informação via redes sociais, sugerindo pensar como isso pode moldar as relações em nossas vidas, até a discussão das fake news, pós-verdade e desinformação" (UNIVERSIDADE FEDERAL DE SANTA MARIA, 2021, p. 1, grifo nosso). Sem dúvida, a abordagem dessas temáticas subsidia a análise crítica do usuário diante da informação. Por conseguinte, conforme Almeida (2020), a utilização das redes sociais para a divulgação de informações fidedignas potencializa o entendimento do público de que a biblioteca universitária se constitui uma unidade com poder informacional.

A Biblioteca Universitária da Universidade Federal de Santa Catarina (BU/UFSC) também se evidencia no controle da desinformação. Dentre as estratégias comunicacionais desenvolvidas pela BU/UFSC, podemos citar:

$\checkmark$ Instauração do programa de extensão 'Comissão de Confiabilidade Informacional e Combate à Desinformação no Ambiente Digital', o qual promove capacitações e pesquisas, produção de tutoriais e materiais didáticos, elaboração de projetos e organização de eventos com o objetivo de "planejar, executar e institucionalizar pesquisas, ações e serviços da Biblioteca Universitária sobre confiabilidade informacional e o combate à desinformação" (UNIVERSIDADE FEDERAL DE SANTA CATARINA, 2021a, p. 1).

'Especial Covid-19' desenvolvido pela Comissão Permanente de Análises de Conteúdos de Informação, cujo objetivo é promover recursos de informação de caráter científico referentes à Covid-19, disponíveis de forma gratuita pelos editores ((UNIVERSIDADE FEDERAL DE SANTA CATARINA, 2021b);

Do mesmo modo, bibliotecas setoriais da Universidade Federal do Rio de Janeiro publicam frequentemente posts educativos em suas redes sociais sobre:

$\checkmark$ Comportamento frente à pandemia;

Atualizações sobre o Covid-19;

Infodemia, como avaliar fontes de informação e identificar notícias falsas;

Ações de outras instituições e da própria UFRJ para diminuir à desinformação.

Por fim, o Sistema de Bibliotecas e Informação da Universidade Federal do Rio de Janeiro (SiBI/UFRJ) também organizou uma lista de sites, repositórios, editoras, bases de 
Bibliotecas universitárias: uso de estratégias comunicacionais de combate à desinformação no contexto da pandemia Covid-19

dados, periódicos e documentos com informações confiáveis sobre o Coronavírus (UNIVERSIDADE FEDERAL DO RIO DE JANEIRO, 2021). Da mesma forma, de um modo geral, as bibliotecas de universidades brasileiras integram uma coleção de artigos científicos e fontes confiáveis para auxiliar em pesquisas sobre a Covid-19, em seus repositórios institucionais, visando desenvolver habilidades focadas no fortalecimento do pensar crítico dos usuários na avaliação da informação, como um modo de controlar à desinformação.

\section{Considerações finais}

Conclui-se que a sociedade informacional, caracterizada pela revolução tecnológica centrada na informação, trouxe novos desafios para a difusão da informação, como os fenômenos da desinformação e da pós-verdade, os quais impactam negativamente a opinião pública. Desafios esses agravados pela crise sanitária, política, econômica e social que assola a sociedade contemporânea, desencadeada pela pandemia do novo coronavírus.

Nesse cenário, conforme depreendido através dos resultados concebidos por meio dos procedimentos metodológicos utilizados nesse artigo, as bibliotecas universitárias reconheceram a necessidade de aprimorar os seus canais de comunicação com criatividade para compartilhar informações em tempos de pandemia com responsabilidade social.

As Bibliotecas Universitárias analisadas têm desenvolvido estratégias comunicacionais como a elaboração de tutoriais, capacitações, programas e projetos, disponibilizados em seus sites institucionais, e a publicação de drops informativos em suas mídias socias, sobre temáticas relacionadas ao combate à desinformação e à infodemia. Dessa forma, as bibliotecas universitárias cumprem sua função contra a desinformação, ao utilizar efetivamente estratégias comunicacionais no âmbito das mídias sociais, subsidiando a construção de uma opinião pública baseada na verdade.

Não obstante, o papel que a biblioteca universitária admite diante do atual cenário da desinformação prevê mais ações de capacitação no uso de fontes e recursos de informação, de modo a estimular a autonomia e o senso crítico do usuário em relação ao ambiente informacional.

Nesse âmbito, é preciso pensar em alternativas que promovam uma maior visibilidade para os serviços oferecidos e conteúdos disponibilizados pelas bibliotecas universitárias. Para 
tanto, é importante frisar a necessidade de um maior suporte financeiro por parte do governo federal junto às universidades, para o fomento das estratégias comunicacionais de divulgação de conteúdos e elaboração de projetos de extensão contra a desinformação. Nessa direção, almeja-se um maior fortalecimento dos serviços de apoio ao ensino, pesquisa e extensão, no âmbito das universidades.

\section{Referências}

ALMEIDA, Alex Serrano de. As bibliotecas universitárias no combate à infodemia. RevIU: Revista Informação \& Universidade, São Paulo, v. 2, p. 1-19, 2020. Disponível em: http://reviu.febab.org.br/index.php/reviu/article/view/35/31. Acesso em: 09 fev. 2021.

BUENO, Wilson da Costa. Estratégias de comunicação para as mídias sociais. In: BUENO, Wilson da Costa (org.). Estratégias de comunicação nas mídias sociais. Barueri: Manole, 2015. Disponível em:

https://integrada.minhabiblioteca.com.br/\#/books/9788520447437/. Acesso em: 28 fev. 2021.

CASTELLS, Manuel. A sociedade em rede. 8. ed. São Paulo: Paz e Terra, 1999. (A era da informação: economia, sociedade e cultura, v. 1).

CEZAR, K. G.; SUAIDEN, E. J. O impacto da sociedade da informação no processo de desenvolvimento. Informação \& Sociedade: Estudos, João Pessoa, v. 27, n. 3, p. 19-29, set./dez. 2017. Disponível em:

https://periodicos.ufpb.br/index.php/ies/article/view/34305/18967. Acesso em: 09 fev. 2021.

CIPRIANI, Fábio. Estratégia em mídias sociais. Rio de Janeiro: Campus, 2011.

COUTANT, Alexandre. As fake news são sintoma de quê? Fake News e Saúde, Brasília, p. 15-29, 2020. Disponível em: https://www.arca.fiocruz.br/bitstream/icict/42586/2/Fake \%20news\%20e\%20sa\%c3\%bade.pdf. Acesso em: 09 fev. 2021.

DELFINO, S. S.; PINHO NETO, J. A. S. de; SOUSA, M. R. F. de. Desafios da sociedade da informação na recuperação e uso de informações em ambientes digitais. RDBCI: Revista Digital de Biblioteconomia e Ciência da Informação, Campinas, v. 17, p. e019036, 2019. Disponível em: https://periodicos.sbu.unicamp.br/ojs/index.php/rdbci/article/view/ 8655973. Acesso em: 10 fev. 2021.

FARIAS, Luiz Alberto; CARDOSO, Ivelise de Almeida; NASSAR, Paulo. Opinião pública: revoluções digitais na era da pós-verdade. In: FARIAS, Luiz Alberto; LEMOS, Else; REBECHI, Claudia Nociolini. Opinião pública, comunicação e organizações convergências e perspectivas contemporâneas. São Paulo: Abrapcorp, 2020. Disponível em: http://www3.eca.usp.br/sites/default/files/form/biblioteca/acervo/producaoacademica/ 002995853.pdf. Acesso em: 09 fev. 2021.

GÓMEZ, A. I. P. Educação na era digital: a escola educativa. Porto Alegre: Penso, 2015. Ebook (18 p.). Disponível em: https://integrada.minhabiblioteca.com.br/\#/books/ 
Bibliotecas universitárias: uso de estratégias comunicacionais de combate à desinformação no contexto da pandemia Covid-19

9788584290246/. Acesso em: 10 fev. 2021.

GOULART, Andrea Heloiza; MUÑOZ, Ivette Kafure. Desinformação e pós-verdade no contexto da pandemia da Covid-19: um estudo das práticas informacionais no Facebook. Liinc em Revista, Rio de Janeiro, v. 16, n. 2, p. e5397-e5397, 2020. Disponível em: http://revista.ibict.br/ liinc/article/view/5397/5125. Acesso em: 10 fev. 2021.

KERN, Lucas Martins. A biblioteca universitária e a pandemia do novo coronavírus. RevIU: Revista Informação \& Universidade, São Paulo, v. 2, p. 1-21, 2020. Disponível em: http://reviu.febab.org.br/index.php/reviu/article/view/30/36. Acesso em: 09 fev. 2021.

NEMER, David. Desinformação no contexto da pandemia do Coronavírus (COVID19). AtoZ: novas práticas em informação e conhecimento, Curitiba, v. 9, n. 2, p. 113-116, 2020. Disponível em: https://revistas.ufpr.br/atoz/article/view/77227/42052. Acesso em: 10 fev. 2021.

OLIVEIRA, Wanderson Kleber de et al. Como o Brasil pode deter a COVID-19. Epidemiologia e serviços de saúde, Brasília, v. 29, n. 2, e2020044, 2020. Disponível em: http://scielo.iec.gov.br/scielo.php?script=sci_arttext\&pid=S167949742020000200002\&lng=p t\&nrm=iso. Acesso em: 11 fev. 2021.

ORGANIZAÇÃO PAN-AMERICANA DA SAÚDE. Departamento de Evidência e Inteligência para Ação em Saúde. Entenda a infodemia e a desinformação na luta contra a COVID-19. Washington: OPAS, 2020a. Disponível em: https://iris.paho.org/bitstream/ handle/10665.2/52054/FactsheetInfodemic_por.pdf?sequence=14. Acesso em: 09 fev. 2021.

PÓS-VERDADE. In: OXFORD living dictionaries. Reino Unido: Oxford, 2019. Disponível em: https://en.oxforddictionaries.com/definition/post-truth. Acesso em: 09 fev. 2021.

RECUERO, Raquel; SOARES, Felipe. O discurso desinformativo sobre a cura do COVID-19 no Twitter: estudo de caso. E-Compós, Brasília, 10 set. 2020. Disponível em: https://www.ecompos.org.br/e-compos/article/view/2127. Acesso em: 20 jan. 2021.

SILVEIRA, Sergio Amadeu da. Tudo sobre tod@s: redes digitais, privacidade e venda de dados pessoais. Edições Sesc, 2017.

SUAIDEN, Emir José. O papel da biblioteca pública na reconstrução da verdade. Ciência da Informação, Brasília, v. 47, n. 2, 2018. Disponível em: http://revista.ibict.br/ciinf/ article/view/4285/ 3799. Acesso em: 10 fev. 2021.

TOBIAS, Mirela Souza; CORRÊA, Elisa Cristina Delfini. O paradigma social da Ciência da Informação: o fenômeno da pós-verdade e as fake news nas mídias sociais. Revista ACB: Biblioteconomia em Santa Catarina, Florianópolis, v. 24, n. 3, p. 560-579, 2019. Disponível em: https://www.revista.acbsc.org.br/racb/article/view/1529/pdf. Acesso em: 09 fev. 2021.

UNIVERSIDADE FEDERAL DE SANTA CATARINA. Biblioteca Universitária. Comissão de confiabilidade informacional e combate à desinformação no ambiente digital (CIDAD). Florianópolis, 2021a. Disponível em: http://cidad.bu.ufsc.br. Acesso em: 10 fev. 2021. 
UNIVERSIDADE FEDERAL DE SANTA CATARINA. Biblioteca Universitária. Especial Covid-19: recursos científicos. Florianópolis, 2021b. Disponível em:

https://portal.bu.ufsc.br/especial-covid-19. Acesso em: 10 fev. 2021.

UNIVERSIDADE FEDERAL DE SANTA MARIA. Biblioteca Central. Redes sociais, tecnologia e fake news. Santa Maria, 01 fev. 2021. Facebook: @ bcufsm. Disponível em: https://www.facebook.com/bcufsm/photos/a.490325834312567/3979401012071681. Acesso em: 10 fev. 2021.

UNIVERSIDADE FEDERAL DO RIO DE JANEIRO. Sistema de Bibliotecas e Informação. Fontes de informação sobre o Coronavírus. Rio de Janeiro, 2021. Disponível em:

http://sibi.ufrj.br/index.php/ inicio/294-fontes-de-informacao-sobre-o-coronavirus. Acesso em: 10 fev. 2021. 